\title{
Hereditary late-onset Parkinson disease
}

INSERM

\section{Source}

INSERM. (1999). Orphanet: an online rare disease and orphan drug data base. Hereditary late-onset Parkinson disease. ORPHA:411602

Hereditary late-onset Parkinson disease (LOPD) is a form of Parkinson disease (PD), characterized by an age of onset of more than 50 years, tremor at rest, gait complaints and falls, bradykinesia, rigidity and painful cramps. Patients usually present a low risk of developing non motor symptoms, dystonia, dyskinesia and levodopa-induced dyskinesia (LID). 